\title{
PENGARUH SUPERVISI KEPALA SEKOLAH DENGAN TEKNIK KELOMPOK (MEETING) TERHADAP PENINGKATAN PRESTASI KERJA GURU DI GUGUS V NAKULA KECAMATAN SERENGAN SURAKARTA
}

\author{
Ismiyatun \\ UPTD Dikpora Kecamatan Laweyan Surakarta \\ ismiyatun2016@gmail.com
}

\begin{abstract}
The purposes of the research were: 1) to know whether there is influence of the headmaster supervision on the performance of the elementary school teachers in Gugus VNakula of Serengan Sub-district, Surakarta; 2) to know how much the influence of the headmaster supervision on the performance of the elementary school teachers in Gugus V Nakula of Serengan Sub-district, Surakarta. This scientific research applied the School Action Research (SAR) that was an effort of increasing the work discipline of teachers in the teaching learning process through an individual supervision and a technique approach of class visit consisting of two cycles and each cycle consisted of four stages: (1) planning, (2) implementation of action, (3) observation/evaluation, and (4) reflection. This School Action Research was conducted in Elementary Schools all over Gugus V Nakula of Serengan Sub-district, Surakarta Municipality. Gugus V Nakula consisted of 5 elementary schools, 2 public elementary schools and 3 private elementary schools SMP only the national standard in the district of Nusa Penida includes two (2) regions and villages Desa Lembongan Jungutbatu, with the amount of students were 315 (three hundreds and fifteen) students, consisting of 12 (twelve) classes, with the amount of teachers was 31 (thirty one) teachers, 3 (three) people had qualification of S2 (post graduate degree), 28 (twenty eight) people had qualification of S1 (undergraduate degree), 1 (one) person had Diploma I (D1) degree. Based on the results of data analysis, either in cycle I or cycle II, it can be concluded that 1) there was an influence of the headmaster supervision on the performance of 1-6 grades teachers in the elementary schools all over Gugus V Nakula, Serengan Subdistrict, Surakarta. It was proved from the analysis scores in the cycle I which the average percentage was $67.26 \%$ which increased into 78,12\%; 2) The amount of influence of the headmaster supverision on the performance of 1-6 grades teachers in the elementary schools all over Gugus V Nakula, Serengan Sub-district, Surakarta in this research was $10.86 \%$.
\end{abstract}

Keywords: Supervision, implementation planning of characterized learning, increased quality of teaching learning activity

Abstrak: Tujuan dari penelitian ini adalah Sesuai dengan permasalahan yang dijabarkan di atas, maka tujuan penelitian yang hendak dicapai adalah: 1) Untuk mengetahui ada tidaknya pengaruh supervisi kepala sekolah terhadap kinerja guru Sekolah Dasar di Gugus V Nakula Kecamatan Serengan Surakarta; 2) Untuk mengetahui seberapa besar pengaruh supervisi kepala sekolah terhadap kinerja guru Sekolah Dasar di Gugus V Nakula Kecamatan Serengan Surakarta. Karya tulis ilmiah 
ini mengambil bentuk penelitian tindakan Sekolah (PTS) yaitu usaha Meningkatan disiplin kerja guru dalan proses belajar mengajar memalui supervisi individual dengan pendekatan tehnik kunjungan kelas, yang terdiri dari dua siklus dan masingmasing siklus terdiri dari empat tahapan yaitu, (1). perencanaan, (2), pelaksanaan tindakan, (3).observasi/evaluasi, dan (4).refleksi. Penelitian Tindakan Sekolah (PTS) ini dilaksanakan di Sekolah Dasar se Gugus V Nakula Kecamatan Serengan Kota Suakarta. Gugus V Nakula terdiri atas 5 SD , 2 SD Negeri dan 3 SD swasta satusatunya SMP Negeri yang berstandar Nasional di Kecamatan Nusa Penida mewilayahi 2 (dua) desa yaitu Desa Lembongan dan Desa Jungutbatu, dengan jumlah siswa 315 (tiga ratus lima belas) orang, terdiri dari 12 (dua belas) kelas, dengan jumlah guru 31 (tiga puluh satu) orang, 3 (tiga) orang kwalifikasi S2, 28 (dua puluh delapan) kwalifikasi S1, 1(satu) orang D1. Berdasarkan hasil Analisis data baik siklus I dan siklus II dapat disimpulkan bahwa 1) ada pengaruh supervisi kepala sekoah terhadap pengingkatan kinerja guru kelas 1-6 di SD segugus V Nakula kecamatan Serengan Surakarta. Ini terbukti dari hasil nilai analisis siklus I rata-rata persentasenya adalah $67,26 \%$ meningkat menjadi 78,12\%;2) Besarnya pengaruh supervisi kepala sekolah terhadap kinerja guru kelas 1-6 SD se gugus V Nakula kecamatan Serengan Surakarta dalam penelitian ini adalah $10,86 \%$

Kata Kunci: Supervisi, RPP berkarakter, kualitas KBM meningkat

\section{Pendahuluan}

Dalam pelaksanaan fungsi dan tugasnya, guru sebagai profesi menyandang persyaratan tertentu sebagaimana tertuang di dalam Undang-Undang Republik Indonesia Nomor 20 tahun 2003 tentang Sistem Pendidikan Nasional. Dalam pasal 39 (1) dan (2) dinyatakan bahwa: Tenaga kependidikan bertugas melaksanakan administrasi, pengelolaan, pengembangan, pengawasan, dan pelayanan teknis untuk menunjang proses pendidikan pada satuan pendidikan.

Untuk dapat melaksanakan tugas dan tanggung jawab diatas, seorang guru dituntut memiliki beberapa kemampuan dan ketrampilan tertentu. Kemampuan dan ketrampilan tersebut sebagai bagian dari kompetensi profesionalisme guru. Kompetensi merupakan suatu kemampuan yang mutlak dimiliki oleh guru agar tugasnya sebagai pendidik dapat terlaksana dengan baik.

Tugas guru erat kaitannya dengan peningkatan sumber daya manusia melalui sektor pendidikan, oleh karena itu perlu upaya-upaya untuk meningkatkan mutu guru untuk menjadi tenaga profesional. Agar peningkatan mutu pendidikan dapat berhasil. Sebagaimana dikemukakan oleh Tilaar (1999:104) peningkatan kualitas pendidikan tergantung banyak hal, terutama mutu gurunya.Menurut UU No.20 tahun 2003 tentang Sistem Pendidikan Nasional bahwa pendidikan adalah usaha sadar dan terencana untuk mewujudkan suasana belajar dan proses pembelajaran agar peserta didik secara aktif mengembangkan potensi dirinya untuk memiliki kekuatan spiritual keagamaan, pengendalian diri, kepribadian, kecerdasan, akhlak mulia, serta ketrampilan yang diperlukan dirinya, masyarakat, Bangsa dan Negara.

Untuk menjadikan guru sebagai tenaga profesional maka perlu diadakan pembinaan secara terus menerus dan berkesinambungan, dan menjadikan guru sebagai tenaga kerja perlu diperhatikan, dihargai dan diakui keprofesionalannya.

Berdasarkan kenyataan yang ada di Sekolah Dasar di Gugus Nakula Kecamatan 
Serengan belum maksimal dilakukan supervisi dan masih banyak kendala atau persoalan yang berkaitan dengan pelaksanaan supervisi oleh kepala sekolah. Partisipasi guru untuk di supervisi masih rendah, mereka beranggapan bahwa supervisi adalah pengawasan atau penilaian yang akhirnya konditebaginya, maka beberapa guru masih enggan untuk disupervisi.

Bertitik tolak dari uraian di atas maka penulis tertarik untuk mengadakan penelitian dengan judul "Pengaruh Supervisi Kepala Sekolah Terhadap Kinerja Guru Sekolah Dasar di Gugus V Nakula Kecamatan Serengan Surakarta Tahun Ajaran 2013/2014”. Sesuai dengan permasalahan yang dijabarkan di atas, maka tujuan penelitian yang hendak dicapai adalah: 1) Untuk mengetahui ada tidaknya pengaruh supervisi kepala sekolah terhadap kinerja guru Sekolah Dasar di Gugus V Nakula Kecamatan Serengan Surakarta; 2) Untuk mengetahui seberapa besar pengaruh supervisi kepala sekolah terhadap kinerja guru Sekolah Dasar di Gugus V Nakula Kecamatan Serengan Surakarta.

\section{Metode}

Karya tulis ilmiah ini mengambil bentuk penelitian tindakan Sekolah (PTS) yaitu usaha Meningkatan disiplin kerja guru dalan proses belajar mengajar memalui supervisi individual dengan pendekatan tehnik kunjungan kelas, yang terdiri dari dua siklus dan masing-masing siklus terdiri dari empat tahapan yaitu, (1) perencanaan, (2) pelaksanaan tindakan, (3) observasi/evaluasi, dan (4) refleksi.

Penelitian Tindakan Sekolah (PTS) ini dilaksanakan di Sekolah Dasar se Gugus
V Nakula Kecamatan Serengan Kota Surakarta. Gugus V Nakula terdiri atas 5 SD, 2 SD Negeri dan 3 SD swasta satu-satunya SMP Negeri yang berstandar Nasional di Kecamatan Nusa Penida mewilayahi 2 (dua) desa yaitu Desa Lembongan dan Desa Jungutbatu, dengan jumlah siswa 315 (tiga ratus lima belas) orang, terdiri dari 12 (dua belas) kelas, dengan jumlah guru 31 (tiga puluh satu) orang, 3 (tiga) orang kwalifikasi S2, 28 (dua puluh delapan) kwalifikasi S1, 1 (satu) orang D1.

Obyek Penelitian dari penelitian tindakan sekolah ini adalah untuk menerapkan supervisi terhadap 30 orang kepala sekolah dengan teknik kelompok yaitu pendekatan pertemuan/ rapat (meeting) untuk meningkatan prestasi kerja guru dalam proses belajar mengajar. Untuk mengumpulkan data dalam Penelitian Tindakan Sekolah ini menggunakan metode pengamatan/obsevasi dengan menggunakan instrumen diatas.

\section{Hasil dan Pembahasan}

Dari hasil analisis data hasil pengamatan dan dari administrasi perangkat pembelajaran guru-guru yang telah di konversi sesuai dengan kualifikasi yang telah ditetapkan dan setelah di analisis maka dapat digambarkan pada tebel dan grafik dibawah ini,

Tabel 5. Analisis Siklus I dengan Siklus II

\begin{tabular}{|c|c|c|c|}
\hline ASPEK & $\underset{\text { I }}{\text { SIKLUS }}$ & $\begin{array}{c}\text { SIKLUS } \\
\text { II }\end{array}$ & $\uparrow$ \\
\hline Jumlah NILAI RIIL & 80,71 & 93,74 & 13,03 \\
\hline Nilai PERSENTASI & 67,26 & 78,12 & 10,86 \\
\hline Kualifikasi & B & A & \\
\hline
\end{tabular}

Sumber: Analisis data primer 
ANALISIS NILAI KINERJA GURU SIKLUS I, II \& PENINGKATAN

KINERJA

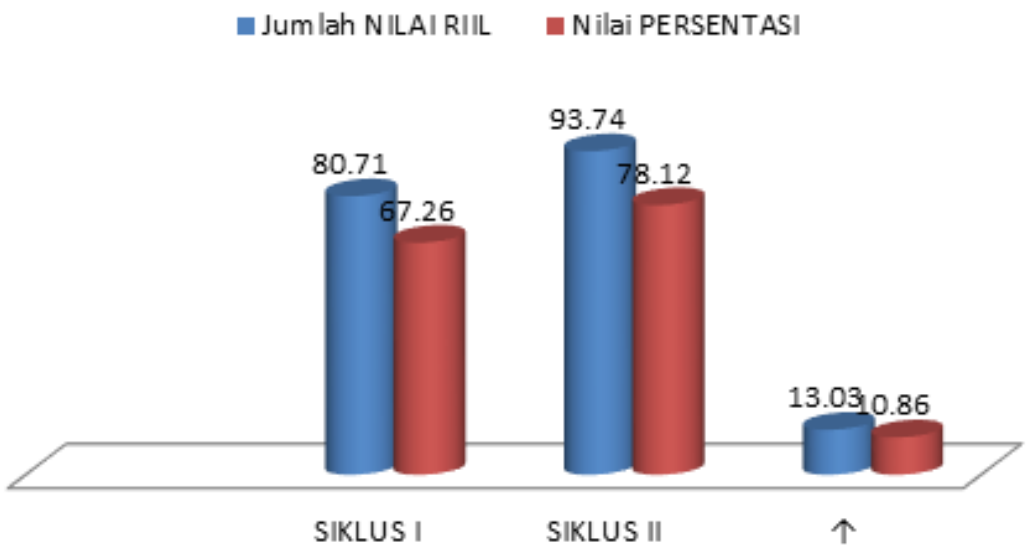

Grafik 5. Rata-rata Perubahan Nilai Hasil Pengamatan Siklus I dan Siklus II

Sumber: Analisis data primer

Gambar dalam tabel 5 diatas adalah hasil analisis siklus I dan analisis pada siklus II terdapat peningkatan sebesar $10,85 \%$, ini berarti ada pengaruh supervisi kepala sekolah terhadap prestasi kerja guru-guru SD di gugus V Nakula kecamatan Serengan Surakarta.

\section{Simpulan}

Penelitian Tindakan Sekolah ini di laksanakan sebanyak 2 (dua) siklus yaitu siklus I dilaksanakan pada minggu kedua bulan Agustus 2013 dan Siklus II dilaksanakan pada minggu kedua bulan September 2013, terhadap 30 (tiga puluh ) orang guru diambil seluruhnya jumlah guru kelas 1-6 yang ada di SD se gugus V Nakula kecamatan Serengan Surakarta. Berdasarkan hasil Analisis data baik siklus I dan siklus II dapat disimpulkan bahwa: 1) Ada pengaruh supervisi kepala sekoah terhadap pengingkatan kinerja guru kelas 1-6 di SD segugus V Nakula kecamatan Serengan Surakarta. Ini terbukti dari hasil nilai analisis siklus I rata-rata persentasenya adalah $67,26 \%$ meningkat menjadi $78,12 \%$; 2) Besarnya pengaruh supervisi kepala sekolah terhadap kinerja guru kelas 1-6 SD se gugus V Nakula kecamatan Serengan Surakarta dalam penelitian ini adalah 10,86\%.

\section{Daftar Pustaka}

Andriani Nutria (2004( Analisis Iklim Organisasi dan Kepuasan Kerja terhadap Kinerja Karyawan pada PT Bank Mandiri Cabang Malang.Universitas Unibra

Arikunto,Suharsini, 1999, Prosedur Penelitian Suatu Pendekatan Praktek Penerbit : Rineka Cipta Jakarta.

Departemen Pendidikan Nasional 2003, Standar Kompetensi Guru Sekolah Menengah Umum, Direktur Tenaga Kependidikan

Jati Sidi, Indra, 2001, Menuju Masyarakat Belajar Menggagas Paradigma Baru Pendidikan ,Penerbit Paramadina, dengan Logos Wacana Ilmu,Jakarta .

Majid,Yusuf A., 2000, Pengaruh Prilaku Pemimpin Terhadap Kinerja dan Kepuasan Kerja Karyawan Pada Industri Kecil Kembang Gula di Kodya Malang,Malang Pasca Sarjana UNIBRA

Nurhadi, (2004), Pembelajaran Contekstual dan Penerapannya dalam KBK. 
PPPPTK, Surya Dharma, (2010) PTS (Penelitian Tindakan Sekolah)

Suharsini A, (2007), Penelitian Tindakan Kelas, Bahan Pelatihan PTK untuk guru, Kepala Sekolah dan Pengawas.

Santyasa I W, (2007), Metodelogi Penelitian Tindakan Kelas, Makalah disajikan dalam pelatihan PTK bagi guru-guru SD di Kabupaten Klungkung.

Santyasa I W, (2007), Model-model Pembelajaran inovatif, disajikandalam pelatihan PTK bagi guru-guru SD di Kabupaten Klungkung.Undang Undang Republik Indonesia Nomor 14. Tahun 2005, Undang-Undang Guru dan Dosen ,Penerbit Cemerlang Jakarta, Tahun 2005 